\title{
EL VIAJE DEL ELEFANTE COMO TEXTO TESTAMENTARIO. JOSÉ SARAMAGO DESDE BYUNG-CHUL HAN
}

\author{
THE ELEPHANT'S JOURNEY AS A TESTAMENTARY TEXT \\ JOSÉ SARAMAGO FROM BYUNG-CHUL HAN
}

\author{
Miguel Alberto Koleff \\ Universidad Nacional de Córdoba (Argentina)
}

\section{ABSTRACT}

The article begins with the understanding that The Elephant's Journey is a testamentary text and, therefore, seeks to find "features" that, allows it to attribute that character from a reflection supported by the texts of the contemporary Korean philosopher Byung-Chul Han, who works as a counterpoint to a thought about contemporary conditions. The text concludes thinking about the philosophical legacy that Saramago left for its readers, from a thorough examination of the notions of "gravity", "duration" "law of the land" and "death".

Key words: testamentary text, philosophy, gravity, death, earthiness.

\section{RESUMEN}

El artículo parte de entender que El viaje del elefante es un texto testamentario y, por lo tanto, se aboca a encontrarle «rasgos» que permitan atribuirle ese carácter a partir de una reflexión apoyada en los textos del filósofo coreano contemporáneo Byung-Chul Han que funciona como contrapunto de un pensamiento situado sobre la condición contemporánea. El texto 
concluye pensando el legado filosófico que Saramago dejó para sus lectores a partir de un examen minucioso de las nociones de «gravedad», «duración» «ley de la tierra» y «muerte».

Palabras clave: texto testamentario, filosofía, gravedad, muerte, terrenalidad.

Fecha de recepción: 20 de noviembre de 2019.

Fecha de aceptación: 11 de diciembre de 2019.

Cómo citar: Koleff, Miguel Alberto (2019): «El viaje del elefante como texto testamentario. José Saramago desde Byung-Chul Han», en Actio Nova: Revista de Teoría de la Literatura y Literatura Comparada, Monográfico 3: 68-80.

DOI: https://doi.org/10.15366/actionova2019.m3.004 
Por varias razones, El viaje del elefante de José Saramago publicado en 2008 puede leerse como su testamento literario. Pueden aducirse, al menos, dos de peso para dar cuenta de esta idea, una de corte experiencial y otra, de tipo discursiva. La primera estriba en la dificultad que tuvo que atravesar el autor para concluir la obra: recordemos que el texto fue escrito en dos etapas, interrumpidas por la grave enfermedad que padeció en 2007. La segunda, y ligada a la emergencia de este hecho, es su propia confesión durante el lanzamiento del libro en São Paulo en la que alude al destino del elefante Salomão, su personaje. En esas palabras, José deja clara la inquietud que norteó su escritura y hace una evaluación de sus efectos de cara a la finitud de la vida. Cito textualmente:

Voltemos rapidamente $\grave{A}$ viagem do elefante. O elefante morreu um ano depois de ter chegado a Viena. Esfolaram-no e cortaram-lhe as patas dianteiras para usálas como recipientes para colocar ali os guardachuvas, as bengalas, os bastões, as sombrinhas. Se não tivesse acontecido isto, que é histórico, eu não direi que não teria escrito o livro, tal vez não o escrevesse, porque aquele corte das patas, aquelas patas que tinham andado milhares de quilómetros até chegar a Viena, no fundo era uma metáfora, quero dizer, da inutilidade da vida. Não conseguimos fazer dela mais do pouco que ela é, quer dizer, que triste fim, não é, que triste fim! Por isso, este elefante deve a sua existência literaria a essa circunstância

[https://www.youtube.com/watch?v=9O-FU7MHm64]

Walter Benjamin solía recordarnos que «la muerte es la sanción de todo lo que el narrador puede referir. De ella tiene prestada su autoridad» (Benjamin, 2008: 75) y el propio Saramago, al referirse al tema, parece ser fiel a esa tarea porque ese largo cuento tiene que ver con el camino recorrido, con la muerte y con la pervivencia o no de la memoria que se materializa en alguno de los restos de aquello que hemos asido durante el tránsito por este mundo. Para nosotros, los lectores del escritor portugués de toda la vida, hay allí una enseñanza que se trasmite como legado y que se puede resumir en una expresión que hace honor al libro, la «filosofía del elefante». Con ella no sólo somos fieles al autor sino que de pies juntillas- subscribimos a su arte de narrar. 
Ahora bien, como toda empresa filosófica que se precie de tal, lleva implícita una serie de principios que se exponen orgánicamente y que, si bien no dan cuenta de un sistema en sentido estricto, están atravesados por líneas fuerza que potencian su valor y legitimidad de cara a lo que se quiere transmitir. Y en el caso puntual que nos ocupa, la «filosofía del elefante» es un muestrario sin equívocos. José Saramago apuesta a la narración por cualquier otra forma expresiva, vigoriza la experiencia por sobre las vivencias singulares y hace de la muerte el leitmotiv de la propia vida. Al poner en escena un animal de importante porte, reflexiona al mismo tiempo sobre la solidez de nuestras prácticas, la opacidad de la cultura y el sentido de gravedad que mueve nuestras acciones y nuestra pertenencia al mundo. Por último, y sin reducir su implicancia, nos alecciona sobre la «ley de la tierra» de la que nunca debemos apartarnos. Para acompañar la reflexión y hacerla profusa, hemos elegido apoyarnos en los textos de Byung-Chul Han, el filósofo surcoreano contemporáneo, ya que su lectura del mundo actual, la por él llamada «sociedad de la transparencia», nos permite instalar una perspectiva dialéctica nada desdeñable.

Aunque los tópicos no estén separados unos de otros, como vía de inicio nos atendremos a la articulación de narración, experiencia y muerte que nos ofrece el libro porque allí se conjugan algunas de las ideas centrales que pretendemos recuperar. Todos sabemos - por la incidencia del discurso benjaminiano en nuestra cultura- que «el arte de narrar ha llegado a su fin» sin, por ello, claudicar del todo. A las fuentes propuestas por el filósofo alemán, es decir, el periodismo de la época que imponía el rigor de la noticia por sobre la del relato, hay que sumarle internet que a través de los linkeamientos continuos nos mantiene al día respecto de cualquier novedad que se produce en el mundo y en forma casi instantánea. La información ha desplazado a la narración, al menos en términos cuantitativos y de velocidad, de eso no caben dudas. Vivimos a expensas del «dataísmo»${ }^{1}$ (Han, 2018b: 87) -como plantea Han- porque el dato puro y simple ha ganado terreno en nuestra cultura. Pero lo más importante es que -como señala este autor- «el final de la narración tiene una consecuencia temporal. Es el final del tiempo lineal. Los acontecimientos ya no se encadenan formando una historia» sino que se disponen en red a

\footnotetext{
${ }^{1}$ En La salvación de lo bello Han escribe una breve sentencia que no puede pasar desapercibida: «Ese 'final de la teoría' que Chris Anderson proclamó, donde la teoría es completamente reemplazada por datos, significa el final de la verdad, el final de la narración, el final del espíritu. Los datos son meramente aditivos. La adición se opone a la narración. A la verdad le es inherente una verticalidad. Los datos y las informaciones, por el contrario, habitan lo horizontal» (Han, La salvación de lo bello, 2019 [2015]: 82). Más enfático resulta cuando después de una exposición del mismo orden concluye que «las metáforas son relaciones narrativas» (103) porque entra en la frecuencia del «elefante» saramaguiano que convocamos en este trabajo.
} 
diferencia del «encadenamiento narrativo» que «opera por medio de una selección y fija con firmeza la sucesión de los hechos» (Han, 2019a: 79) y su sentido.

No hay argumento posible que nos haga pensar que a Saramago se le haya pasado de largo esta premisa cuando decide legarnos una trayectoria en su texto testamentario, el del largo recorrido que realiza el elefante Salomão y el cornaca Subho desde Portugal a Viena venciendo un conjunto de obstáculos orográficos difíciles de sortear. Lo que sucede es que tanto para el autor como para la fuente bibliográfica consultada, la sola linealidad no asegura nada si no viene cargada de tiempo hasta estallar. De allí que -desde Benjamin en adelante- el concepto de narración vaya ligado necesariamente al de experiencia [Erfharung] porque ésta implica una duración. La experiencia que se cuece en el tiempo es la que posibilita «la fuerza ordenadora» del relato (27) y la que le provee su «tensión dialéctica» (20). En palabras de Han, «los acontecimientos ya no se ordenan sobre una superficie estática, sino en una línea ininterrumpida» (30) y por esta razón, «la historia ilumina, selecciona y canaliza el enredo de los acontecimientos, (imponiéndole) una trayectoria narrativa lineal» (36).

Lo que Saramago reconoce -y que al «dataísmo» en general y los dataístas, en particular- se les escapa, es que la narración contribuye a nuestro desempeño humano en el mundo. Por eso, la aventura de un elefante indiano existe como certeza y como posibilidad, de igual manera. Se trata de un libro que contiene innumerables datos históricos, algunos contrastables de manera más fácil que otros y a los que se pueden acceder vía web sin dificultad alguna pero que -no obstante- están organizados según la lógica del relato y no de la adición informativa. Hay que seguir a Han y el juego terminológico que introduce para entender estas razones. Según su punto de vista, «narrar una historia (Eræählen) es un modo concreto de contar (zählen). Construye una tensión, que dota de sentido a la sucesión de los acontecimientos. Los enlaza más allá del mero recuento (Zäblen), lo que da lugar a una historia (Geschichte)» (78). La deconstrucción del verbo «contar»-potenciada a través de su etimología en alemán- a caballo entre la literatura y la matemática, marca con elocuencia la disfuncionalidad de la que el vocablo se ha adueñado en los nuevos tiempos.

Hay que advertir -también- que aunque nuestra época contemporánea haga gala de la «desnarrativización» (entnarrativisieung) (54) de los hechos presentándolos como cifras desnudas, la facticidad épica sigue siendo el instrumento central de la filosofía porque le da cuerpo a la experiencia. No hay modo de que esta se realice en abstracto y por fuera de los condicionamientos empíricos como tampoco existe la posibilidad de atravesar los Alpes sin 
experimentar temor y temblor como los vividos por Subhro y el elefante Salomão al interactuar con una nieve desacostumbrada. Como sucede con las patas del elefante, la narrativa se hunde en el lodo de las propias circunstancias y no puede desprenderse de ellas con solo evocar la evidencia.

Precisamente, el aspecto más desasosegador que esta constatación comporta tiene que ver con la conciencia de los propios personajes que saben que su derrotero está tajeado por el dolor del propio existir. El dolor -como manifestación de la negatividad ${ }^{2}$, en términos de Han- habla de una «continuidad temporal que estabiliza» (21), la única que asegura una «vida plena» (26) que no se realiza a sus márgenes, menos aún confabulándose con imágenes autofingidas. Es esa misma negatividad que se sustancia en y como relato, la que «implica un vínculo, una relación y una proximidad dado que sólo las relaciones intensivas hacen que las cosas sean reales» (74). De allí la potencia de los vínculos que la narrativa mantiene intacta.

No quiero olvidarme, en este punto, de la diferencia que realiza Han entre «peregrino» y «turista» (54) a partir de los conceptos de Zygmunt Bauman porque el caso del cornaca Subhro lo desnuda al detalle. En la despedida del comandante de Portugal que acompañó la expedición hasta Valladolid como en la llegada al destino previsto, en Austria, cuando se separa del archiduque Maximiliano, el cornaca evalúa las transformaciones que experimentó durante el largo tránsito y se sabe modificado por las circunstancias. En la perspectiva del filósofo coreano, es esta conciencia de la «facticidad» la que lo convierte en peregrino porque da por entendido el arco trazado entre el «allí» del punto de partida y el «aquí» del punto de llegada en que las mudanzas se procesan experiencialmente. En otras palabras, Subhro no es el mismo al inicio que al final ${ }^{3}$. El camino lo ha ido diseñando y moldeándole el carácter y la actitud. El cambio de nombres sufrido al atravesar la frontera pasa a ser sólo un accidente al lado de las implicaciones existenciales a las que debió enfrentarse. A diferencia del peregrino, el turista posmoderno se mueve entre un aquí y un allí que no le incide en absoluto más que en el plano de la interioridad. Turistas -en este

\footnotetext{
${ }^{2}$ El concepto de «negatividad» que es opuesto al de «positividad» no aparece nunca definido en los libros de Byung-Chul Han salvo como dato contrastivo para expresar el segundo que es su verdadero eje de intelección. Aun así, algunas frases sueltas de los diferentes textos ayudan a precisarlo como esta de La salvación de lo bello: «la actual sociedad positiva elimina cada vez más la negatividad de la herida» (53) donde «herida» convoca las imágenes negativas asociadas al dolor y al sufrimiento.

${ }^{3}$ Es importante esta constatación porque el «conocimiento» es una «negatividad» para Han y sólo puede ser producto de la experiencia. Obsérvese esta cita de Han, «al acontecimiento le es inherente una negatividad, pues engendra una relación nueva con la realidad, un mundo nuevo, una comprensión nueva de lo que es. Hace que de pronto todo aparezca bajo una luz totalmente distinta» (Han, La expulsión de lo distinto. Percepción y comunicación en la sociedad actual, 2018 [2016]: 15).
} 
sentido de Han- pueden ser los carroceros de la expedición portuguesa que eligen volver a través de Porto para conocerlo y aprovecharse de la oportunidad que les posibilitó un viaje inesperado.

Hechas estas consideraciones, debemos decir que es un paso decisivo incorporar la noción de realidad si queremos hablar de la muerte que sobreviene al final de todas las cosas y hacerlo abiertamente. El último capítulo del libro de Saramago nos la presenta de cara descubierta y sin las falsas premisas con que se la evitan a la reina consorte. Coincidiendo con Han, el autor portugués entiende que la narración posee un talento especial para acabar y concluir desde el momento en que hace de la muerte «el final resultante del tiempo de la vida» (22). «Morir en el momento justo» es la gran preocupación de todos los narradores del mundo. «Sólo las formas temporales del final generan, contra la terrible infinitud, una duración, un tiempo pleno, lleno de significado» (22). El caso que ocupa nuestra atención, la muerte del elefante Salomão coadyuva a esta idea transformada en legado desde el momento en que nos muestra una vida completa henchida de experiencia que ha llegado a su fin. La sobrevivencia de las patas que caminaron el extenso territorio europeo, transformadas hoy un porta-paraguas se constituye en una cifra que alternativamente- nos habla de la finitud a la que estamos sometidos y de la superfluidad de nuestro paso por este mundo pese a todo.

II

Detengámonos ahora en las implicancias éticas de este planteo. Analizar A viagem do elefante desde una perspectiva filosófica resulta una actividad estimulante, sobre todo si tomamos como punto de partida las consideraciones teóricas de Byung-Chul Han como lo estamos haciendo. $\mathrm{Y}$ esto, porque nos permite encarar el trabajo desde un lugar inusitado como lo suponen las variables de la duración, la transparencia y la gravedad a través de las cuales vamos costurando nuestro planteo.

Para asumir este desafío, en este segundo abordaje, elijamos concentrarnos imaginéticamente en la figura del elefante, que es el protagonista de la historia y reconocer los elementos constructivos con los que ha sido trazado. Más allá de la trama organizada en torno de su recorrido histórico y de los personajes - célebres y no célebres- que le dan razón y sentido, la sola presencia del animal con su imponente presencia ocupa el centro de 
la escena. Y -si como anticipamos en la entrada anterior- el texto de José Saramago es «testamentario» en sentido estricto, alguna lógica ha de encerrarse en esta elección.

Han mediante, vamos a definir a la imagen -en perspectiva heideggeriana- como el medio a través del cual nos apoderamos del ente y lo tenemos a disposición (Han, 2018a: 78). Es decir, vamos a recurrir a una conceptualización clásica porque la duración, la opacidad y la gravedad con que nos es transmitida la figura de Salomão poco tiene que ver con «las imagénes mediáticas de hoy, que no pasan de simulacros que ya no representan ningún ente (78). Al decir de Han, ellas «pululan más allá del poder y del dominio. Son en cierto modo más entitativas y vivas que el ente» (78). Es claro que ninguna de las criaturas construidas por Saramago pueden ser asequibles de esta manera ya que ellas detentan siempre fuerza y solidez, y por eso no se apartan del paradigma clásico.

Hecha esta aclaración necesaria, empecemos por considerar la descripción física que aparece en la página 22 del cuento cuando es definido como un «proboscídeo de mais de quatro côvados de altura» (Saramago, 2008a: 22), reforzada después en la página 85 en ocasión de describir las dificultades de la travesía. A saber, «olhe que ele tem três metros de altura e pesa umas quarenta toneladas, se não mais» (85).

La sola información del volumen del animal en cuestión nos pone en alerta, no sobre la ruta que debe seguir ya que ésta se cumple a rajatabla sino sobre la demora que supone llevar a cabo el viaje. Vemos como se tensiona mucho al comienzo del libro y se relaja sobre el final debido a los medios utilizados. Se percibe con nitidez que la marcha a pie anuda los efectos retardadores de la acción acompañando el ritmo sincopado del animal como así también que hay un claro esfuerzo en el cuento en mensurar cada detalle de la secuencia narrativa de modo que las grandes síntesis cronológicas no conspiren en contra de la armonía. Siguiendo al pensador coreano podríamos decir que el autor portugués opera con los diversos matices de la «duración» para que no se pierda el eje del relato, que es el propio transcurrir y no la llegada a la meta. El tiempo concentrado de la marcha constituye lo que el filósofo denomina «la prolífica semántica del camino» (61). Es ella la que convierte una ruta en una experiencia y no la reduce a un derrotero, es ella la que moviliza peregrinos y no turistas conforme antes señalamos. Dicho de otra manera, «el intervalo temporal que se extiende entre dos situaciones o acontecimientos es un tiempo de transición» (Han, 2019a: 60) que valora la pausa, la cesura, el tiempo justo de cada acción, sin la prisa de lo cotidiano y arrasador. Como texto testamentario, A viagem do elefante apuesta a ese compás existencial de sus lectores. 
El segundo aspecto a considerar forma parte de la negatividad de la experiencia a la que también alude Han y se resuelve por vía opuesta a su concepto de «transparencia». Para ilustrarlo con claridad nada mejor que convocar la imagen física del elefante y asociarla a las instancias de exposición y culto a la que es sometido durante el viaje. La primera, la exposición, es la más relevante de todas a raíz del tamaño que hace difícil que pase imperceptiblemente. Sabemos, por el curso del relato, que el elefante es exhibido a la comunidad y por eso llama la atención de la población por cada lugar que atraviesa. El «valor de exposición»-de raíz benjaminiana- es el articulador de la «transparencia» de todas las cosas en la medida en que «todo está vuelto hacia fuera, descubierto, despojado, desvestido y expuesto» (Han, 2018a: 29). Pero, partiendo de la propia evidencia, es imposible pensar que el elefante pueda ser asociado a los atributos de la posmodernidad que releva Han, tales como la hipervisibilidad, la nitidez, el diafanismo o la fosforencia debido a que su propia matriz existencial desmiente estos extremos. Aun así, como se trata de efectos publicitarios de tipo fetichista, es fácil hacer creer una cosa por otra frente a una comunidad que desconoce el rigor de estas cuantías. Pensemos en la venta de los pelos del animal en Trento y pensemos también en los falsos milagros realizados por Salomão. Ahora bien, si concordamos con el filósofo coreano en que «las imágenes se hacen transparentes cuando son liberadas de toda dramaturgia, coreografía y escenografía, de toda profundidad hermenéutica y de todo sentido» (12) en el caso que nos ocupa, la imagen artificial se eclipsa y se fortalece por la «condensación semántica y temporal» (28) de una puesta en escena, que se reitera en cada una de las circunstancias en las que Salomão parece decidido a imponer su presencia. Es el valor positivo de la «masa» que no se reduce a «adiposis, masificación y excrecencia» (59) como en la sociedad actual, sino que resguarda «lo oculto, lo inaccesible y lo misterioso» (30). En este gesto de Saramago, puede leerse también la matriz de la herencia cultural ya que frente a la opacidad de Salomão no hay ningún efecto de transparencia que lo substraiga de su condición terrenal y lo enajene como vil mercancía. Si bien en nuestro tiempo «la coacción de la exposición explota lo visible» (31) el procedimiento se oblitera porque no se pone a su servicio. Por más que se intente, el «desvelamiento no puede hacer desaparecer lo encubierto» (46) y de este modo, el cuerpo crea su propio lenguaje.

Una breve digresión acerca del concepto de belleza. Es cierto que Saramago nos presenta coherentemente la figura del elefante y por lo tanto, no hay ninguna nota discordante que resalte su lindura o fealdad. Para el autor portugués, está claro que la 
animalidad de Salomão es la que le provee los atributos que lo destacan y que calificarla es asignarle una nota de valor que pertenece más al terreno de la subjetividad humana que de la verdad en sentido preciso. Lo que sí queda claro y esto no puede obviarse con facilidad es que hay un cuidado especial en no presentar al personaje con esas categorías artificiales que Han detecta en los parámetros estéticos de la posmodernidad y que sintetiza con los atributos de «liso, pulido, satinado y terso» (Han, 2019b: 29). En este sentido, la implicación del cuerpo con la belleza no se desentiende de las funciones excretoras que tanto caracterizan a Salomão durante la vasta caminata, como así también su voracidad a la hora de comer o de beber. Y esto sin contar, los perjuicios a los que se expone durante la travesía (los hielos adheridos a su pelo, por ejemplo). El caso de la gualdrapa es significativo porque -sin considerar los riesgos del circuito a recorrer- apunta a adornarlo, tornarlo artificioso a los ojos a los que ha de exponerse. La retirada posterior, debido a la incomodidad que le genera y a la inclemencia que daña a la tela, hay que entenderla como un retorno a las condiciones originarias de la travesía o lo que es lo mismo, la recuperación de la propia animalidad.

Para cerrar este tópico y dar paso al tercero, hay que hacer algunos señalamientos más respecto de la «mirada» y de lo que Han denomina la «contigüidad epidérmica entre ojo e imagen» (32) recuperando los conceptos benjaminianos de «cercanía» y «lejanía» asociados a su idea de aura. Si consideramos - en consecuencia- que «la coacción de la exposición, que lo entrega todo a la visibilidad, hace desaparecer por completo el aura como una aparición de una lejanía» (26) no sucede de esta manera en el caso del elefante Salomão porque este no pierde nunca la distancia necesaria con quienes lo rodean y es ella la que asegura su autonomía e independencia pese la obstinada pretensión de transformarlo en una posesión imperial ${ }^{4}$.

Concentrándonos ahora en el tercer aspecto que exige una atención de nuestra parte hemos de abocarnos a la consideración del efecto gravitacional que soporta el peso del elefante. Han se ha ocupado del tema en el libro ya referenciado sobre el aroma del tiempo al señalar que «la fuerza de gravedad que marca la trayectoria de las cosas va desapareciendo lentamente. Las cosas, liberadas de sus referencias de sentido, empiezan a flotar y a dar tumbos sin dirección... se alejan las unas de las otras por falta de gravitación

\footnotetext{
${ }^{4}$ No desarrollo con agudeza este tema para no ir más allá de las posibilidades de este trabajo, pero dejo sentada una posición apoyándome en Han. Cuando él afirma que «a lo bello natural le es inherente una lejanía» (Han, 2019b: 42) está señalando que «su aura de lejanía lo sustrae a todo consumo» (42).
} 
de sentido» (Han, 2019a: 41). En su perspectiva, la sociedad contemporánea acompaña con cierta complicidad los efectos amortiguadores de la realidad tornando las cosas más livianas y soportables de lo que eran en el pasado. Al hacerlas disponibles, las libera de su enraizamiento material potenciándolas de una fluidez más transparente y menos radical de lo que se espera de ellas. Así, «la falta de gravitación provoca que las cosas se aíslen en átomos vacíos de sentido» (42). En franca oposición con esta perspectiva, el elefante Salomão es la representación misma de la gravedad por el peso que soporta y por su fijación al terreno en donde se apoya. Por más tentativas que quieran hacerse al respecto, es difícil demover al animal de la actitud que asume debido a que no es materialmente posible conducir sus movimientos sin aliarlos a su complicidad.

Si los seres humanos podemos creer en virtualidades desprovistas de asentamientos concretos, no sucede así con la especie animal que -a su modo y con eficacia- sostiene la «ley de la tierra» ${ }^{5}$. Esta expresión corresponde a uno de los capítulos de Han desarrollados en En el enjambre y que muestran su gratitud y correspondencia con el pensamiento de Heidegger, a quien reconoce como el «último gran defensor del orden terreno» (Han, 2017a: 77) en el plano filosófico. La constatación del pensador coreano es radical, en esta perspectiva: «en el curso del giro digital abandonamos definitivamente la tierra, el orden terreno: somos liberados de la gravedad y del carácter incalculable de la tierra, estamos arrojados a una situación sin soporte» (77). Muy coherente -por otro lado, con las reflexiones elaboradas en los últimos anos y reunidas en su último libro Loa a la tierra (2017 [2019]) en la que se leen frases como las de este tipo:

La digitalización aumenta el ruido de la comunicación. No solo acaba con el silencio, sino también con lo táctil, con lo material, con los aromas, con los colores fragantes, sobre todo con la gravedad de la tierra. La palabra humano viene de humus, tierra. La tierra es nuestro espacio de resonancia que nos llena de dicha. Cuando abandonamos la tierra nos abandona la dicha (Han, 2017b: 14).

O

\footnotetext{
5 También en La salvación de lo bello hay referencias a este tema: «El nomos de la tierra del que habla Schmitt es un paradigma que hemos abandonado hace tiempo a cambio de lo digital. El orden digital desplaza todos los parámetros del ser. «Propiedad», «vecindad», «clan», «estirpe» y «estamento» se encuadran todos ellos en el orden terreno, en el orden de la tierra. La interconexión digital disuelve el clan, la estirpe y la vecindad» (Han, 2019b: 74).
} 
La digitalización elimina la propia realidad. O la realidad se des-realiza y acaba reducida a una ventana dentro de lo digital. Nuestro campo visual pronto parecerá una pantalla tridimensional. Cada vez nos alejamos de la realidad. Mi jardín es para mí la realidad recuperada (15).

Hay un claro punto de encuentro entre el pensador coreano y el escritor portugués en estas reflexiones. Podríamos incluso hablar de una misma frecuencia ya que en su texto testamentario José Saramago también propone la «ley de la tierra» como basamento teórico para la actuación del hombre en la historia, la política, la economía y la sociedad. La mirada de estos dos interlocutores -que hablan en silencio en este escrito- no está tan apartada como podría pensarse a simple vista. ¿Será quizá porque «não é todos os días que aparece nas nossas vidas um elefante?» (Saramago, 2008a: 65). 


\section{BIBLIOGRAFÍA}

Benjamin, W. (2008): El Narrador, (traducción al español de P. Oyarzun Robles) Santiago de Chile, Metalespesados.

Han, B.-C. (2017a): En el enjambre, (traducción al español de R. Gabás), Buenos Aires, Herder, [2013].

Han, B.-C. (2017b): Loa a la tierra, CABA, Herder, [2019].

Han, B.-C. (2018a): La sociedad de la transparencia, (traducción al español de R. Gabás) Buenos Aires, Herder, [2012].

Han, B.-C. (2018b): Psicopolítica. Neoliberalismo y nuevas técnicas de poder, (traducción al español de A. Bergés), Buenos Aires, Herder, [2014].

Han, B.-C. (2018c): La expulsión de lo distinto. Percepción y comunicación en la sociedad actual, (traducción al español de A. Ciria) Buenos Aires, Herder, [2016].

Han, B.-C. (2019a): El aroma del tiempo. Un ensayo filosófico sobre el arte de demorarse, (traducción al español de P. Kuffer), Buenos Aires, Herder, [2009].

Han, B.-C. (2019b): La salvación de lo bello, (traducción al español de A. Ciria), Buenos Aires, Herder, [2015].

Saramago, J. (2008a): A viagem do elefante, Lisboa, Caminho.

Saramago, J. (2008b): El viaje del elefante, Buenos Aires, Alfaguara. 
SOBRE EL AUTOR

\section{Miguel Alberto Koleff}

Profesor Titular Regular. Literaturas en Lengua Portuguesa. Facultad de Lenguas. Universidad de Córdoba. Miguel A. Koleff trabaja en el campo de las Literaturas afro-lusobrasileñas en la Facultad de Lenguas de la Universidad Nacional de Córdoba donde cumple tareas de docencia, investigación y extensión, tanto en el grado como en el posgrado. Es Coordinador Académico de la Cátedra Libre José Saramago en la misma Facultad y autor de varias publicaciones, entre las que se destacan La caverna de José Saramago: una imagen dialéctica (EDUCC, 2013), Vence también a los leones (Ferreyra Editor, 2015) y El perro de las lágrimas y otros ensayos de literaturas lusófonas (Ferreyra Editor, 2027) al lado de numerosos papers académicos. Es Director por el lado argentino de la Revista de Estudos Saramaguianos cuya sede está en Brasil. Escribe regularmente en la Columna de Literaturas Lusófonas del diario Hoy día Córdoba. Es Director de la Maestría en Lenguaje e Interculturalidad de la Facultad de Lenguas UNC.

Contact information: correo electrónico: miguelkoleff@gmail.com 